\title{
11. HIGH-RESOLUTION ROCK-MAGNETIC STUDY OF CEARA RISE SEDIMENTS AT SITE 925ำ
}

\author{
Peter A. Solheid, ${ }^{2}$ Subir K. Banerjee, ${ }^{2}$ Carl Richter, ${ }^{3}$ and Jean-Pierre Valet ${ }^{4}$
}

\begin{abstract}
A variety of rock-magnetic measurements was made on sediment samples from Ceara Rise, Leg 154, Site 925 of the Ocean Drilling Program. Ceara Rise sediments are composed of marine carbonates and terrigenous material from the Amazon Fan. Bulk susceptibility, which measures approximately the concentration of strongly magnetic particles (e.g., magnetite, maghemite) in the sediment, can be used as a climate proxy signal that is based on the dilution of terrigenous material by oceanderived carbonates. During interglacial periods, the high-susceptibility terrigenous material is diluted, resulting in a minimum in susceptibility. This hypothesis is supported by the inverse correlation between the smoothed susceptibility record and the $\delta^{18} \mathrm{O}$ low latitude record. Anhysteretic remanent magnetization (ARM), contributed primarily by magnetic grains from 0.1 to $15 \mu \mathrm{m}$, was normalized by susceptibility $(\chi)$, giving a parameter that is sensitive to magnetic grain size. Variations of ARM/ $\chi$ show high values during interglacials and low values during glacials. The source of this material is most likely from an increase of Amazon Basin soil runoff during interglacial periods.
\end{abstract}

\section{INTRODUCTION}

Ceara Rise $\left(5^{\circ} \mathrm{N} 44^{\circ} \mathrm{W}\right)$ is located just north of the equator, approximately $700 \mathrm{~km}$ from the mouth of the Amazon River (Fig. 1) where it intersects the Atlantic Ocean's deep water flow paths (Curry, Shackleton, Richter, et al., 1995). The sediment is composed of marine carbonates and terrigenous material delivered from the Amazon Basin. The sediment covers the entire Cenozoic in age and ranges in thickness from 950 to $1300 \mathrm{~m}$. Five sites were cored during Leg 154 of the Ocean Drilling Program (ODP) to complete a bathymetric transect from Site 925 at a depth of $3040 \mathrm{~m}$ to Site 929 at a depth of $4355 \mathrm{~m}$. The sediments for our study came from Site 925, which is the shallowest of the five sites and located well above the Carbonate Compensation Depth (CCD) (Curry, Shackleton, Richter, et al., 1995).

The sediments consist mainly of clay, calcareous nannofossils, and foraminifers in varying amounts. The top $30 \mathrm{~m}$ consist of grayish brown nannofossil clay with foraminifers alternating with light brownish gray clayey nannofossil ooze with foraminifers. Below this interval, from 30 to $135 \mathrm{mbsf}$, the sediments consist of nannofossil ooze with varying amounts of foraminifers and steadily increasing clay towards the top of the subunit (Curry, Shackleton, Richter, et al., 1995). A composite section was constructed by splicing together sections of different cores by matching overlapping magnetic susceptibility and color data to create a continuous sedimentary section (Hagelberg et al., 1992). The composite section for Site 925 consists of cores from Holes 925A, 925B, and 925C resulting in a continuous sediment record measured in meters composite depth (mcd) for most of the upper $300 \mathrm{~m}$ from the middle Miocene to the late Pleistocene (Curry, Shackleton, Richter, et al., 1995).

A multi-parameter rock-magnetic study was conducted on these sediments to seek a high-resolution rock-magnetic proxy signal of climate cycles, possibly both at Milankovitch and sub-Milankovitch in scale. Various rock-magnetic measurements were made in order to

${ }^{1}$ Shackleton, N.J., Curry, W.B., Richter, C., and Bralower, T.J. (Eds.), 1997. Proc. ODP, Sci. Results, 154: College Station, TX (Ocean Drilling Program).

${ }^{2}$ Institute for Rock Magnetism, University of Minnesota, Minneapolis MN 554550128, U.S.A.peat@tc.umn.edu.

Ocean Drilling Program, 1000 Discovery Drive, Texas A\&M University, College Station, TX 77845-4857, U.S.A.

${ }^{4}$ Institut de Physique du Globe, 4 Place Jussieu, 75252 Paris Cedex 05, France.

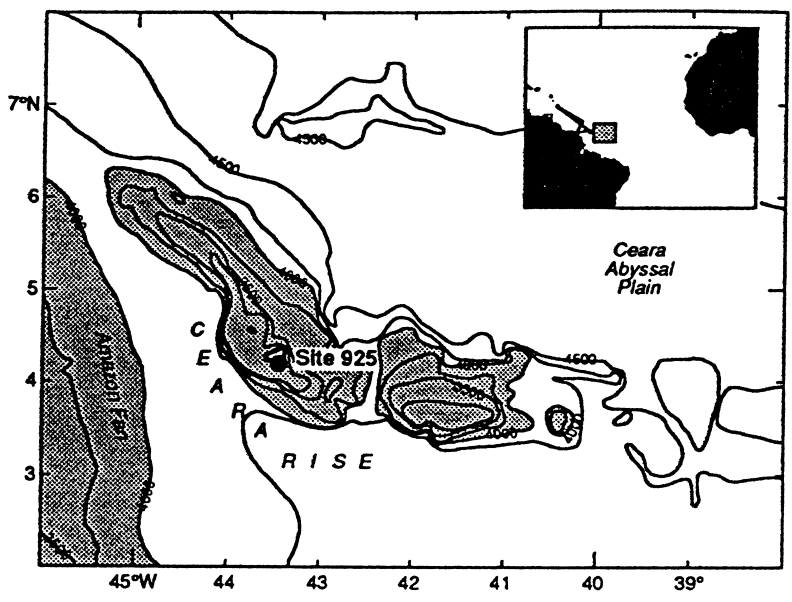

Figure 1. Location map of Ceara Rise showing Site 925 (Mountain and Curry, 1995).

determine concentration, grain size, and composition of the magnetic grains for the top 6 mcd of the composite section. Based on nannofossil dates determined on board, the sedimentation rate is approximately 40 mcd/m.y. (Curry, Shackleton, Richter, et al., 1995). At 6 mcd, the age of the sediment should be 150 k.y.

\section{SAMPLING AND EXPERIMENTAL METHOD}

Low-field magnetic susceptibility $\left(\chi_{l f}\right)$ and anhysteretic remanent magnetization (ARM) were measured at room temperature $(300 \mathrm{~K})$. Hysteresis parameters were measured next at room temperature for selected samples. For selected samples, low-field magnetic susceptibility and saturation isothermal remanent magnetization (SIRM) were measured as a function of temperature, both lower and higher than $300 \mathrm{~K}$.

\section{Room Temperature Measurements}

Samples were selected from Sections 154-925C-1H-1 through $1 \mathrm{H}-4$ to provide a high resolution record of deposition encompassing $\delta^{18} \mathrm{O}$ 
Stages 1-6. A total of 214 samples were taken in unoriented $2.5 \mathrm{~cm}^{3}$ sample tubes at 2- to 5-cm intervals and then transferred for magnetic measurements into standard spectroscopy cuvets cut to $1 \mathrm{~cm}^{3}$ cubes. Measurements were made in order of increasing magnetic field intensity so that previous measurements would not affect later measurements. Low-field magnetic mass susceptibility $\chi_{l f}$ was measured for each sample in a Kappabridge model KLY-2 susceptibility bridge (Geofyzika Brno) with an inducing field of $3.8 \times 10^{-4} \mathrm{~T}$. Low field susceptibility is contributed by the ferrimagnetic, antiferromagnetic, paramagnetic, and diamagnetic components of the sample. The measurements were corrected for the susceptibility of the empty cube $\left(-9.21 \times 10^{-8} \mathrm{~m}^{3} / \mathrm{kg}\right)$ and normalized to mass. Repeated measurements show the error from this source to be less than $0.5 \%$. The samples were then given an ARM in a modified Schonsted demagnetizer, by applying a small $\left(50 \times 10^{-6} \mathrm{~T}\right)$ DC biasing field superimposed on a decaying alternating field with a peak value of $100 \mathrm{mT}$. The samples were then measured on a $2 \mathrm{G}$ Enterprises 3-axis cryogenic magnetometer, and values were normalized to mass. The empty cubes have no measurable ARM greater than the error, estimated to be $1 \%$ from repeated measurements. Following this, hysteresis loops were measured on selected samples on a vibrating sample magnetometer (VSM) and normalized to mass. From the hysteresis measurements we obtained parameters related to magnetic mineralogy and grain size: saturation magnetization $\left(\sigma_{s}\right)$, which is the magnetization at $0.75 \mathrm{~T}$ (corrected for the linear response of dia-, para-, and antiferromagnetic constituents). High-field susceptibility $\left(\chi_{h f}\right)$ was determined by calculating the slope of the closed high-field $(0.6-0.75 \mathrm{~T})$ portion of the loop. $\chi_{h f}$ is a measurement of the antiferromagnetic, diamagnetic, and paramagnetic content of the sample.

\section{Temperature Dependent Measurements}

We selected 10 samples to examine the magnetic mineralogy with low temperature SIRM. Approximately $0.15 \mathrm{~g}$ of material is cooled down to $20 \mathrm{~K}$ and exposed to a $2.5 \mathrm{~T}$ magnetic field for 20 seconds. At this temperature even the finest grains are thermally stable and can acquire a remanence. The sample is then gradually warmed to room temperature while the SIRM is measured in zero field at $5 \mathrm{~K}$ intervals. From these measurements, certain magnetic minerals can be identified by characteristic spin transitions at which a loss of remanence occurs at a characteristic temperature. Susceptibility vs. temperature was also measured on approximately $0.15 \mathrm{~g}$ of sample from room temperature to $700^{\circ} \mathrm{C}$ on a furnace-equipped, Kappabridge model KLY-2 susceptibility bridge modified with flowing Argon gas. Upon heating, at the Curie point the thermal energy overcomes the magnetic ordering of the ferri- and antiferromagnetic content, the weak magnetic field is no longer able to induce a magnetization in the sample, and susceptibility is reduced to zero. Ferri- and antiferromagnetic minerals can be identified by this method.

\section{RESULTS}

\section{Magnetic Susceptibility}

Low-field magnetic susceptibility shows variations with wavelengths in the order of 20 to $100 \mathrm{~cm}$ (Fig. 2). The values range from 4 $\times 10^{-8}$ to $1.6 \times 10^{-7} \mathrm{~m}^{3} / \mathrm{kg}$. The measurements agree well with the whole core susceptibility measurements made on board the JOIDES Resolution. The discrete samples provide a higher resolution and show smaller scale variations that cannot be detected with the pass-through equipment. Magnetic susceptibility is predominantly affected by the concentration of magnetic grains but can be affected by grain size as well. Measurements made on board ship show that susceptibility is negatively correlated to calcium carbonate and therefore predominately a carbonate concentration proxy (Curry, Shackleton, Richter, et al., 1995). Magnetic susceptibility correlates inversely with the low-latitude $\delta^{18} \mathrm{O}$ stack (Bassinot et al., 1994) (Fig. 3). The agreement between the two

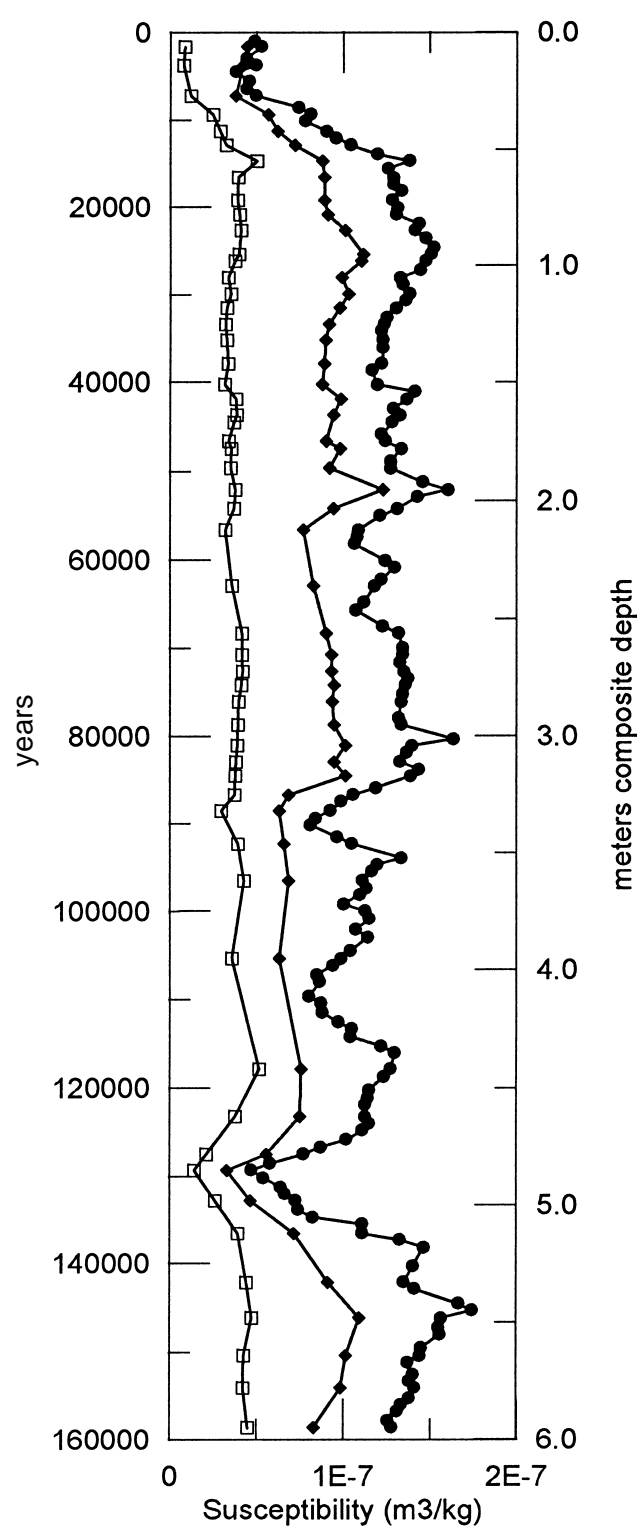

Figure 2. Low-field (solid circles) and high-field (open squares) susceptibility variations with depth. Note that all of the features of $\chi_{l f}$ remain after $\chi_{h f}$ is subtracted (solid diamonds). Left y-axis shows years.

data sets leads us to confirm the preliminary shipboard interpretation. Para- and diamagnetic susceptibility are contributed by clay, quartz, carbonates, and other non-iron-bearing minerals. $\chi_{h f}$ is contributed mainly by paramagnetic clay and diamagnetic minerals (calcium carbonate). High-field susceptibility $\left(\chi_{h f}\right)$ as described above is small in magnitude and varies from $1 \times 10^{-8}$ to $6 \times 10^{-8} \mathrm{~m}^{3} / \mathrm{kg}$. By subtracting $\chi_{h f}$ from $\chi_{l f}$ we can obtain the contribution of the ferrimagnetic portion (or magnetite) of the sediment (Fig. 2). This calculation indicates that the variations in susceptibility are primarily due to the ferrimagnetic concentration.

\section{Anhysteretic Remanence Magnetization}

The ARM varied from $4.5 \mathrm{E}-5$ to $9.5 \mathrm{E}-5 \mathrm{Am}^{2} / \mathrm{kg}$ indicating a change in the concentration of fine single-domain (SD) to pseudosingle-domain (PSD) magnetite and other ferrimagnetic minerals. Measurements of ARM show a positive correlation with susceptibil- 


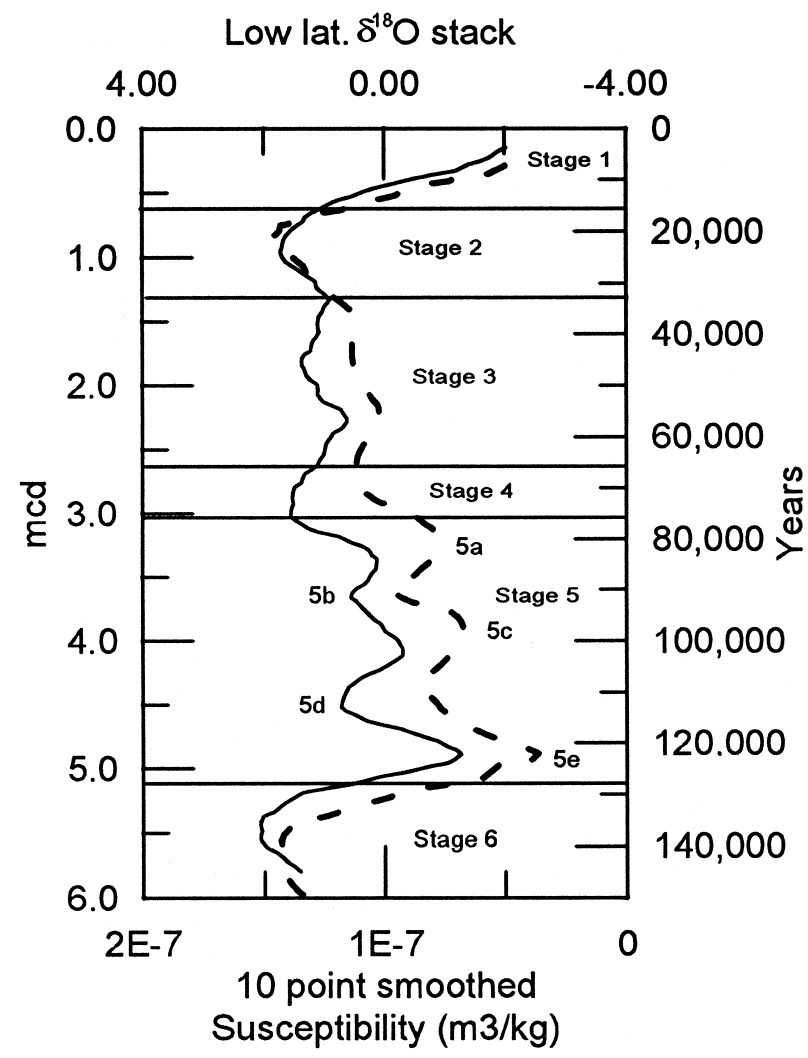

Figure 3. Comparison of 10-point smoothed susceptibility (solid line) and the low-latitude $\delta^{18} \mathrm{O}$ stack of Bassinot et al., 1994 (dashed line). The high degree of correlation implies that variations in susceptibility are induced by climate change.

ity from 1 to 3 mcd (Fig. 4). Above and below this region the correlation breaks down and even appears to become negatively correlated below 3 mcd.

\section{Hysteresis Parameters}

Hysteresis parameters are shown in Figure 5. The saturation magnetization $\left(\sigma_{s}\right)$ varies from $0.3 \times 10^{2}$ to $9 \times 10^{2} \mathrm{Am}^{2} / \mathrm{kg}$ and saturation remanence $\left(\sigma_{r s}\right)$ varies from $0.5 \times 10^{-3}$ to $2.2 \times 10^{-3} \mathrm{Am}^{2} / \mathrm{kg}$. Coercivity $\left(H_{c}\right)$ ranges from 12.5 to $18 \mathrm{mT}$ and coercivity of remanence $\left(H_{c r}\right)$ ranges from 35 to $50 \mathrm{mT}$. All magnetic minerals contribute to $\sigma_{s}$ while $\sigma_{r s}$ is sensitive only to the concentration of SD and multidomain (MD) ferromagnetic particles. $H_{c}$ and $H_{c r}$ are dependent on both mineralogy and grain size. There is a sharp drop in $H_{c}$ and $H_{c r}(3.5$ and $13 \mathrm{mT}$ respectively) at about $1 \mathrm{mcd}$; below this depth $H_{c}$ and $H_{c r}$ remain fairly constant. A comparison of the ratios $\sigma_{s} / \sigma_{s}$ to $H_{c r} / H_{c}$ yields information about the domain state and hence the grain size of the magnetic particles (Day et al., 1977; Dunlop, 1986). The average value of $\sigma_{r s} / \sigma_{s}$ is 0.22 and the average value of $H_{c r} / H_{c}$ is 2.6 . Figure 6 shows the data clustered in the center of the PSD region on a plot of the hysteresis ratios (Day et al., 1977).

\section{Temperature Dependent Results}

Susceptibility vs. temperature measurements show a strong peak between $250^{\circ}$ and $300^{\circ} \mathrm{C}$ that is twice the amplitude of the baseline. A second peak occurs between $450^{\circ}$ and $550^{\circ} \mathrm{C}$ just prior to the Curie point where the susceptibility drops to zero. Figure 7 shows two characteristic $\chi_{l f}$ vs. temperature curves from samples from above and be-

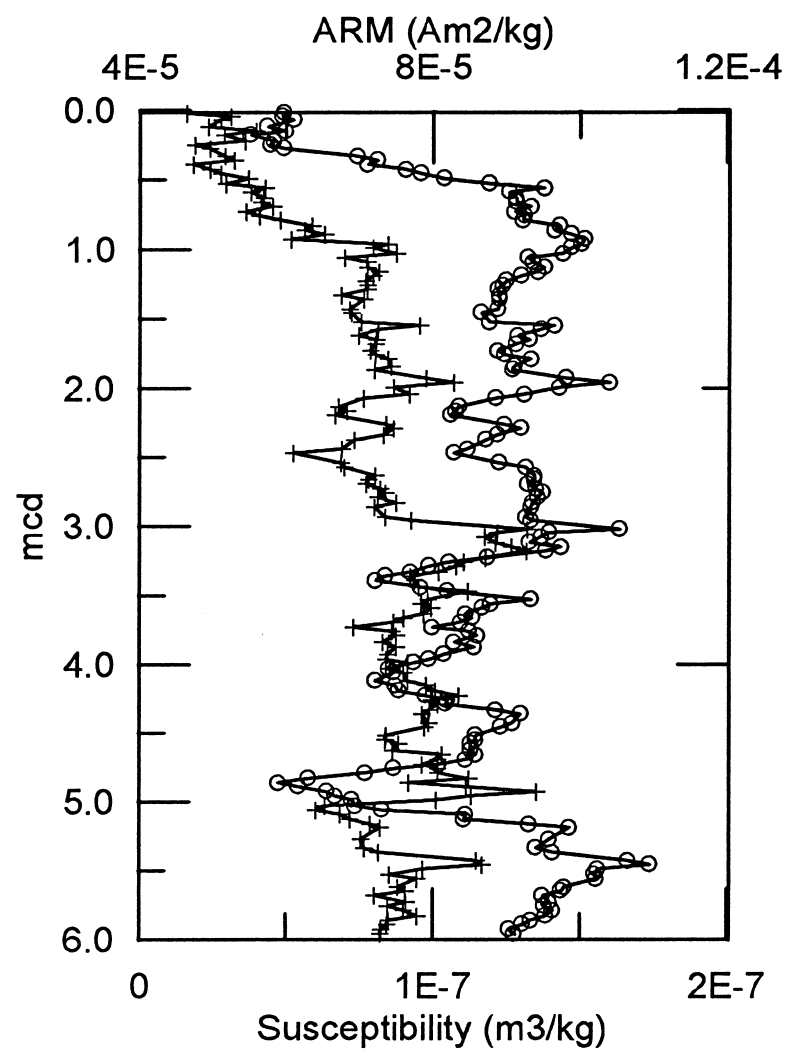

Figure 4. Downcore variations of susceptibility (open circles) and anhysteretic remanent magnetization (+). Between 1 and 4 mcd the susceptibility and ARM are correlated.

low the coercivity drop at $1 \mathrm{mcd}$. The peak between $250^{\circ}$ and $300^{\circ} \mathrm{C}$ indicates the possible presence of pyrrhotite (Rochette et al., 1990) both above and below the coercivity drop. The loss of susceptibility near $580^{\circ} \mathrm{C}$ (the Curie point of magnetite) indicates that magnetite is the dominant magnetic mineral present in the samples. Low-temperature decay of saturation isothermal remanent magnetization in zero ambient field show high gradients of decrease of remanence between 20 and 60 $\mathrm{K}$ and gradual decay of remanence to $300 \mathrm{~K}$ following a step transition at $110 \mathrm{~K}$. Figure 8 shows the decay of SIRM as a function of temperature and the derivative of the decay curve, which reveals small-scale variations in the amplitude and the position of transitions. The sharp decay of SIRM (acquired at $20 \mathrm{~K}$ ) between 20 and $60 \mathrm{~K}$ indicates thermal unblocking in super paramagnetic (SP) ultra fine particles $(<30 \mathrm{~nm}$ for magnetite), (Néel, 1949; Bean and Livingston, 1959; Cullity, 1972; Hunt et al., 1995). Larger grains of magnetite are indicated by the presence of the Verwey transition occurring at $118 \mathrm{~K}$ as indicated by the sharp gradient change of the curves.

\section{DISCUSSION}

\section{Magnetic Mineralogy}

Because of the low concentration of the magnetic phase (see below), it was not possible to identify the magnetic minerals by $\mathrm{x}$-ray diffraction. Hysteresis loops show saturation at fields on the order of $0.2 \mathrm{~T}$, as expected for magnetite or a mineral close to it in composition. Susceptibility vs. temperature curves show a major drop between $550^{\circ}$ and $600^{\circ} \mathrm{C}$, close to the Curie point $\left(580^{\circ} \mathrm{C}\right)$ of pure magnetite. The susceptibility peak between $250^{\circ}$ and $300^{\circ} \mathrm{C}$ is, however, close to $320^{\circ} \mathrm{C}$, the susceptibility peak of pyrrhotite (Rochette et al., 


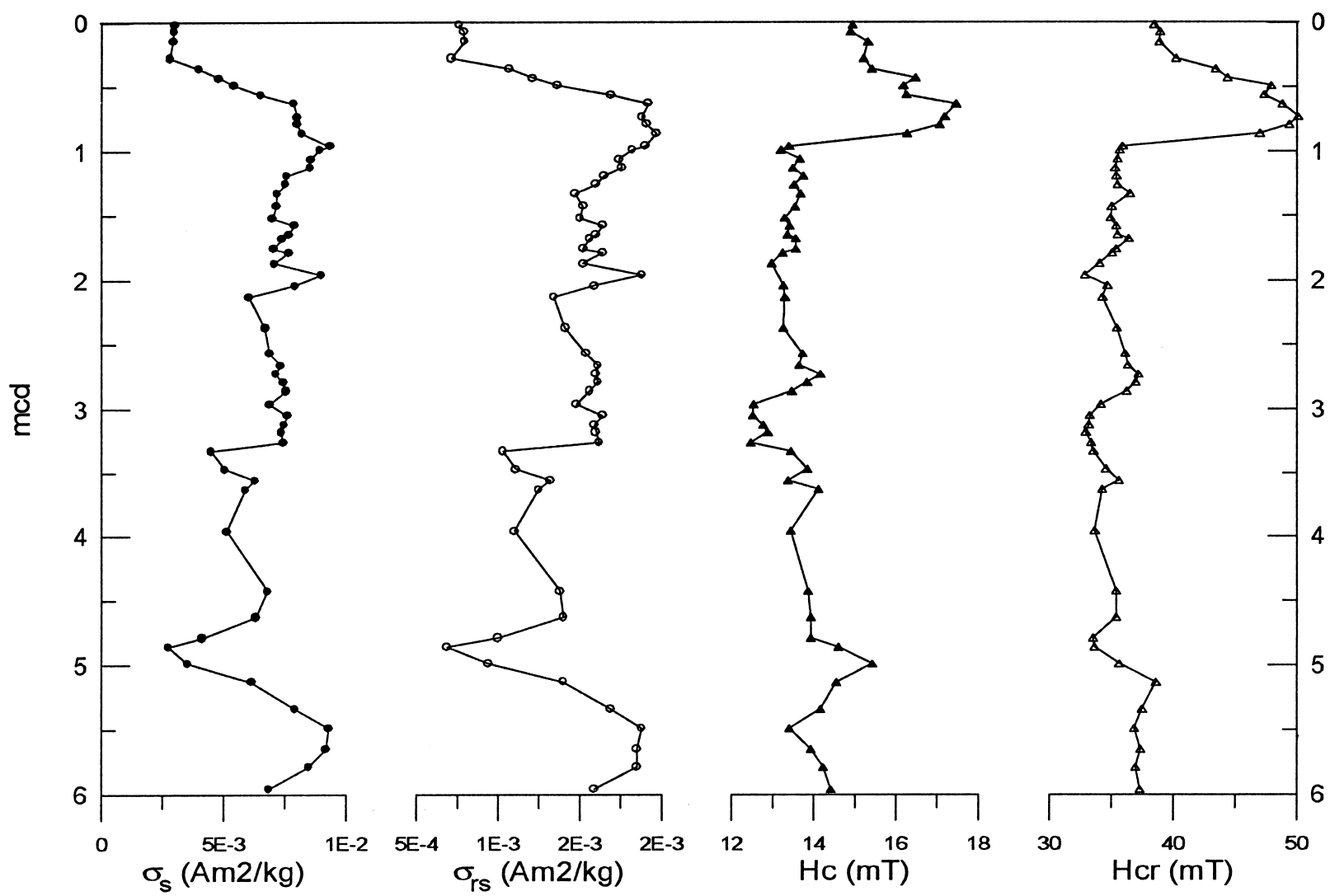

Figure 5. Hysteresis parameters vs. depth. Note the similarity between saturation magnetization $\left(\sigma_{s}\right)$ (closed circles) and saturation remanence $\left(\sigma_{r s}\right)($ open circles), indicating that variations are due to single-domain and larger particles. Coercivity $\left(H_{c}\right)$ (closed triangles) and coercivity remanence $\left(H_{c r}\right)$ (open triangles) show a dramatic drop at near 1 med.

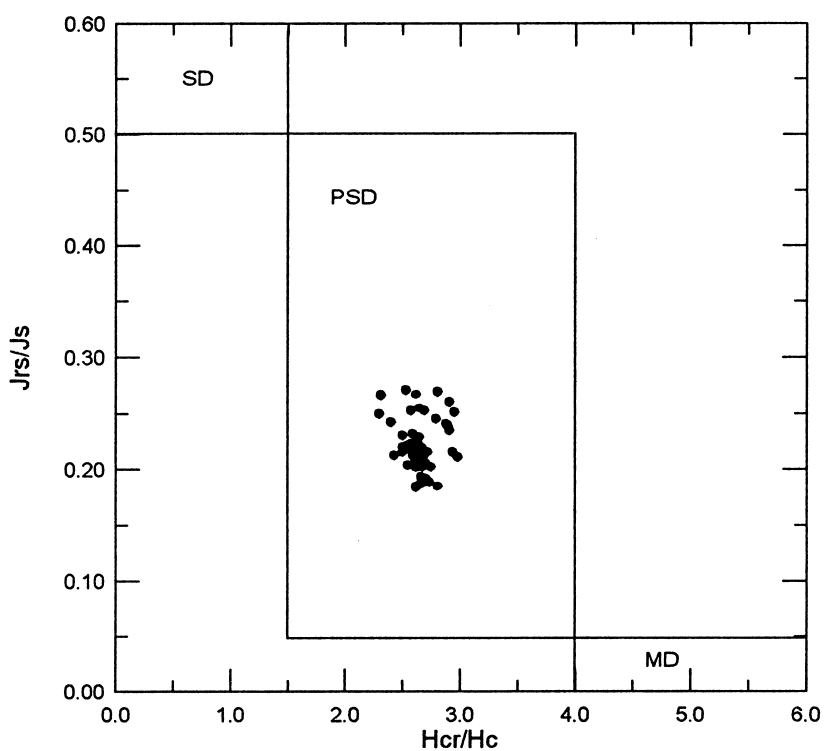

Figure 6. Plot of hysteresis parameter ratios (Day et al., 1977) show that all samples contain magnetite with a relatively uniform pseudo-single-domain grain size.
1990). The best evidence for magnetite comes from the ubiquitous observation of the characteristic Verwey transitions at 118K. Pending future experiments, it is reasonable to conclude that the main magnetic mineral is magnetite.

\section{Magnetite Concentration}

If magnetite is the chief magnetic mineral present, its concentration can be determined by dividing the observed saturation magnetization $\left(\sigma_{s}\right)$ with that expected for pure magnetite, $92 \mathrm{Am}^{2} / \mathrm{kg}$. For most of the samples, i.e., below $0.6 \mathrm{~m}$ depth, average value of $\sigma_{s}$ was $7.5 \times 10^{-3} \mathrm{Am}^{2} / \mathrm{kg}$, leading to a magnetite concentration of $\sim 0.0082 \%$. This is very close to the mean value of $0.0072 \%$ observed by Richter et al. (this volume) for 114 samples from Site 929 . In the top $0.6 \mathrm{~m}$ of our site, average $\sigma_{\mathrm{s}}$ decreases to $\sim 3.5 \times 10^{-3} \mathrm{Am}^{2} / \mathrm{kg}$, leading to a magnetite concentration of $\sim 0.0038 \%$. We suspect that this drop of nearly $54 \%$ is most likely caused by higher water content at the top.

Low-field magnetic susceptibility can be used as a proxy for magnetite concentration as long as grain size does not display a large variability, especially at the lower end (superparamagnetic, diameter $<30$ $\mathrm{nm}$ ) of the size spectrum. As we will show below, the grain size of our samples is very uniform, falling within the middle of the PSD range, between 0.1 and $15 \mu \mathrm{m}$. If dissolution were contributing to the loss of susceptibility we would see a loss of the finer grains, but, as we will show below, the proportion of finer grains increases when susceptibility is low. Therefore, the observed magnetic susceptibility variations about the mean can be interpreted as concentration variation of magnetite and $\mathrm{CaCO}_{3}$ (Curry, Shackleton, Richter, et al., 1995). As we have further shown, the temporal record of susceptibil- 


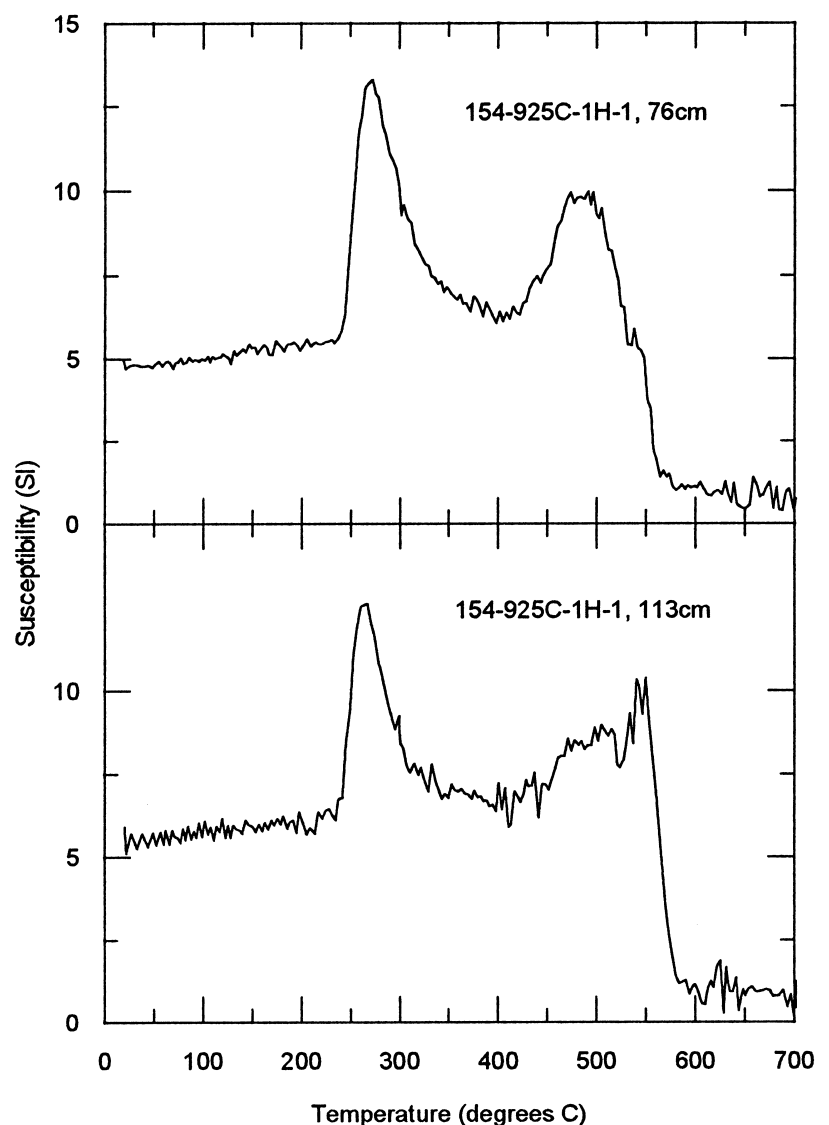

Figure 7. Susceptibility vs. temperature of two samples above (Sample 154925C-1H-1, $76 \mathrm{~cm}$ ) and below (Sample 154-925C-1H-1, $113 \mathrm{~cm}$ ) the drop in coercivity and coercivity remanence at $1 \mathrm{mcd}$. Both samples show a peak near $300^{\circ} \mathrm{C}$, the Curie point of pyrrhotite and a loss of susceptibility near $580^{\circ} \mathrm{C}$, the Curie point of magnetite.

ity at Site 925 is inversely correlated with the low-latitude $\delta^{18} \mathrm{O}$ stack (Bassinot et al., 1994).

\section{Grain-Size Variation}

Average grain-size information for magnetite can be obtained from a plot of the hysteresis parameters $\sigma_{r s} / \sigma_{s}$ vs. $H_{c r} / H_{c}$ (Day et al., 1977). Our data are well clustered in the middle of the PSD sizerange, $0.1-15 \mu \mathrm{m}$ (Fig. 6). A finer scale variation in grain size of magnetite can be obtained from the ratio of $\mathrm{ARM} / \chi$ (Banerjee et al., 1981; King et al., 1982). A high value of the ratio signifies the presence of SD $(\sim 0.1 \mu \mathrm{m})$ and small PSD $(\sim 1 \mu \mathrm{m})$ grains. We find strong increases in $\mathrm{ARM} / \chi$ during the Holocene and the previous interglacial (isotopic stage 5) (Fig. 9). Along with Richter et al. (this volume), we regard the source of the magnetitelmaghemite as the terrigenous sediments composing the Amazon Fan, which is currently the main source of terrigenous material to the Ceara Rise. Therefore, high concentrations of SD and smaller PSD grains are likely from sediment input during interglacials when high rainfall and large surface run-off may have occurred in the Amazon drainage basin.

\section{Diagenesis}

The sharp drop in $H_{c}$ and $H_{c r}$ values at 0.95 mcd in the upper part of the sediment core is most likely a diagenetic effect caused by sulfate reduction (Leslie et al., 1990; Karlin, 1990). This dissolves SD

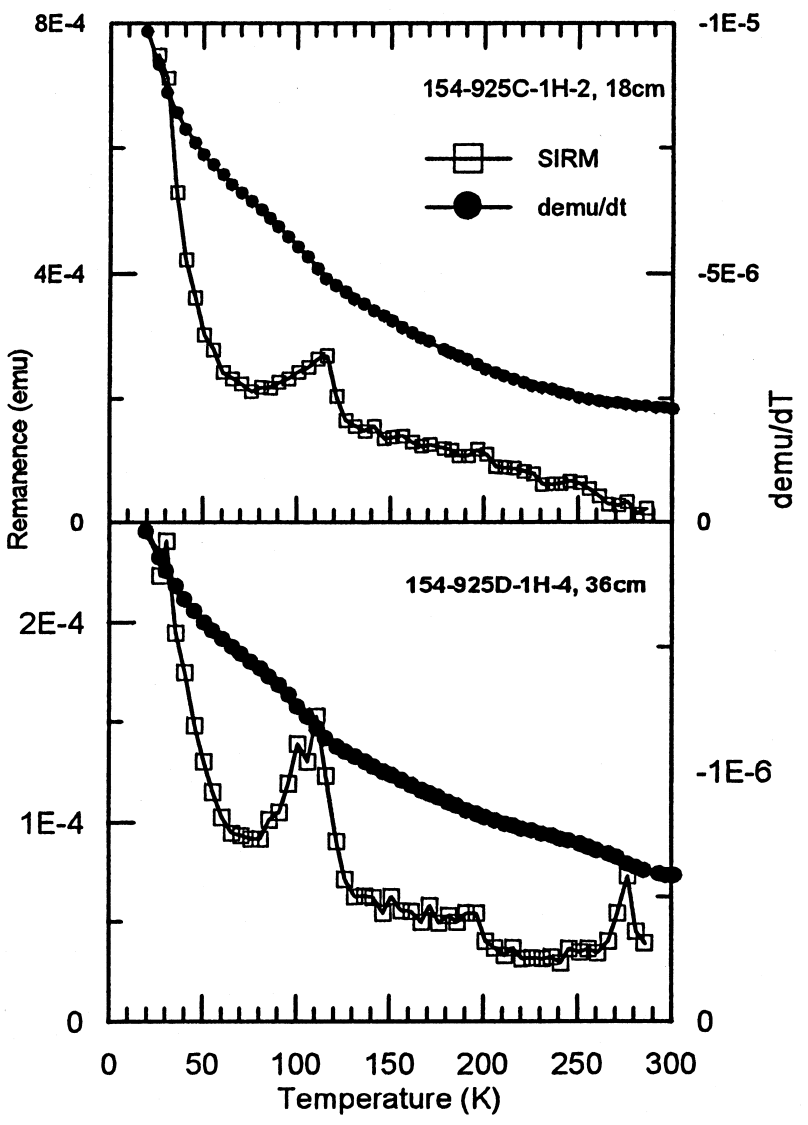

Figure 8. Thermal demagnetization of low temperature saturation isothermal remanent magnetization show that super paramagnetic grains as indicated by the sharp decrease in remanence between 20 and $60 \mathrm{~K}$ and larger grains of magnetite are present as noted by the Verwey transition at $118 \mathrm{~K}$. The derivative of the demagnetization curve clearly shows smaller scale changes in both the magnitude and position of the transition.

magnetite grains with high $H_{c}$ and $H_{c r}$ values. The drop also corresponds to a change in color from reddish brown $(0-0.95 \mathrm{mcd})$ to gray (0.95-6 mcd). Other magnetic parameters are not strongly affected by this drop indicating it may be due to the loss of a high-coercivity but weakly magnetic material such as hematite or goethite. This observation could explain why a corresponding decrease in $\sigma_{s}$ does not exist. Furthermore, the heating experiments show a susceptibility peak at $\sim 275^{\circ} \mathrm{C}$ both above and below the jump in $H_{c}$ values at 0.95 mcd, which suggests the presence pyrrhotite. If sulfate reduction occurred below the $H_{c}$ transition boundary, the pyrrhotite peak should not be present.

\section{CONCLUSION}

A high-resolution record of multiple magnetic proxies at, Site 925 has been obtained for the last $150 \mathrm{k}$.y. Magnetic susceptibility, which is inversely correlated with temperature and $\mathrm{CaCO}_{3}$, shows oscillations that correspond to Milankovitch cycles. Magnetic measurements indicate that the main magnetic carrier is magnetite or maghemite but pyrrhotite may also be present. The concentration of magnetite varies from $0.0038 \%$ above 1 mcd to $0.0082 \%$ below 1 mcd. The average magnetic grain size ranges from $0.1-15 \mu \mathrm{m}$ and is fairly uniform throughout the samples. High values of ARM/ $\chi$ indicate increased fine-grained magnetite $(\sim 0.1 \mu \mathrm{m})$ during interglacials. 


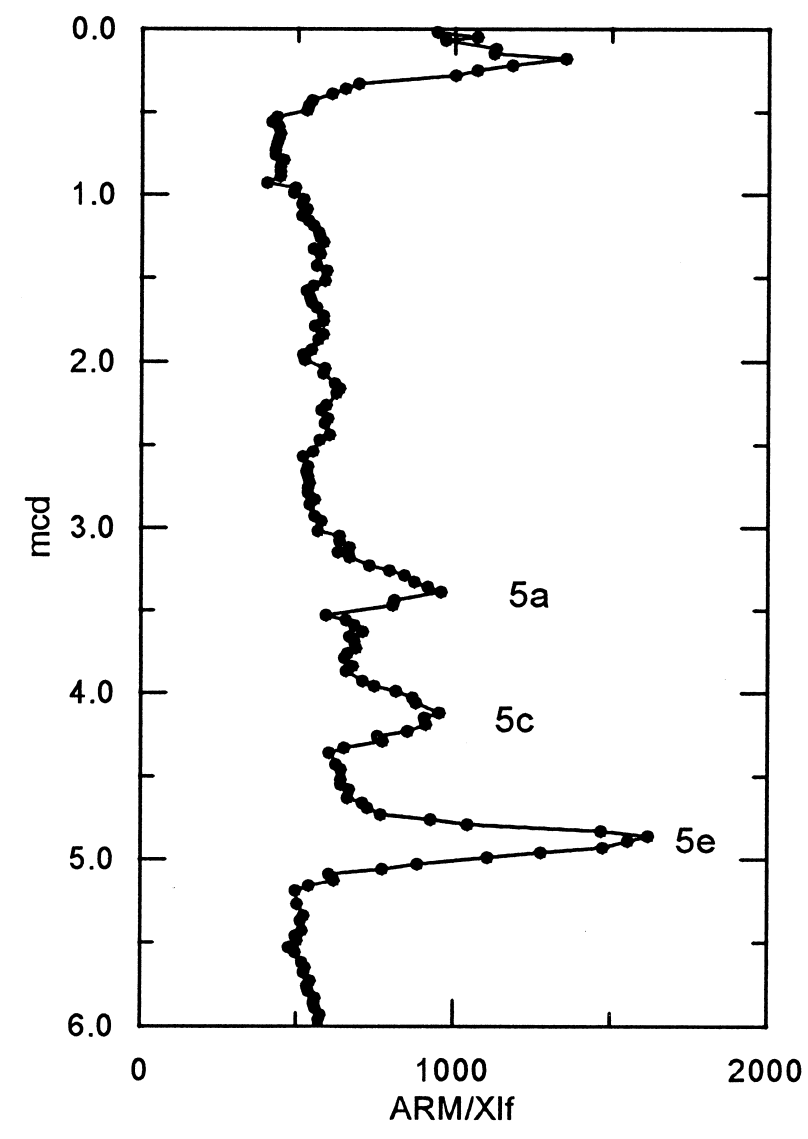

Figure 9. Anhysteretic remanence magnetization (ARM), a grain-sizedependent parameter, normalized to low-field susceptibility (to remove concentration variations), provides a measure for fine single-domain (SD) and small pseudo-single-domain (PSD) grain sizes. During interglacials (0-0.5 mcd and 3.2-5.2 mcd, see Fig. 3) the ratio is some $50 \%-100 \%$ higher than during glacials $(0.5-3.2 \mathrm{mcd})$.

\section{ACKNOWLEDGMENTS}

We thank the crew and scientists aboard the JOIDES Resolution for their support and long days during this high-recovery leg. This paper is contribution No. 9603 of the Institute for Rock Magnetism which is funded by the Keck Foundation, NSF, and the University of Minnesota. We would also like to thank Bernie Housen for discussion leading to this manuscript and Mike Jackson for review, assistance, and discussion in preparing this manuscript.

\section{REFERENCES}

Banerjee, S.K., King, J.W., and Marvin, J., 1981. A rapid method for magnetic granulometry with applications to environmental studies. Geophys. Res. Lett., 8:333-336.

Bassinot, F.C., Labeyrie, L.D., Vincent, E., Quidelleur, X., Shackleton, N.J., and Lancelot, Y., 1994. The astronomical theory of climate and the age of the Brunhes-Matuyama magnetic reversal. Earth Planet. Sci. Lett., 126:91-108

Bean, C.P., and Livingston, J.D., 1959. Superparamagnetism. J. Appl. Phys., 30:120S-129S

Cullity, B.D., 1972. Introduction to Magnetic Materials: Reading, MA (Addison-Wesley).

Curry, W.B., Shackleton, N.J., Richter, C., et al., 1995. Proc. ODP, Init. Repts., 154: College Station, TX (Ocean Drilling Program).

Day, R., Fuller, M., and Schmidt, V.A., 1977. Hysteresis properties of titanomagnetites: grain-size and compositional dependence. Phys. Earth Planet. Inter, 13:260-267.

Dunlop, D.J., 1986. Hysteresis properties of magnetite and their dependence on particle size: a test of pseudo-single-domain remanence models. $J$. Geophys. Res., 91:9569-9584.

Hagelberg, T., Shackleton, N., Pisias, N., and Shipboard Scientific Party, 1992. Development of composite depth sections for Sites 844 through 854. In Mayer, L., Pisias, N., Janecek, T., et al., Proc. ODP, Init. Repts., 138 (Pt. 1): College Station, TX (Ocean Drilling Program), 79-85.

Hunt, C.P., Banerjee, S.K., Han, J.-M., Solheid, P.A., Oches, E.A., Sun, W.W., and Liu, T.-S., 1995. Rock-magnetic proxies of climate change in the loess-paleosol sequences of the western Loess Plateau of China. Geophys. J. Int., 123.

Karlin, R., 1990. Magnetite diagenesis in marine sediments from the Oregon continental margin. J. Geophys. Res., 95:4405-4419.

King, J.W., Banerjee, S.K., Marvin, J., and Özdemir, Ö., 1982. A comparison of different magnetic methods for determining the relative grain size of magnetite in natural materials: some results from lake sediments. Earth Planet. Sci. Lett., 59:404-419.

Leslie, B.W., Lund S.P., and Hammond, D.E., 1990. Rock magnetic evidence for the dissolution and authigenic growth of magnetic minerals within anoxic marine sediments of the California continental borderland. $J$. Geophys. Res., 95:4437-4452.

Mountain, G.S., and Curry, W.B., 1995. Cruise Ew9209: Site survey for Leg 154. In Curry, W.B., Shackleton, N.J., Richter, C., et al., Proc. ODP, Init. Repts., 154: College Station, TX (Ocean Drilling Program), 39-52.

Néel, L., 1949. Théorie du traînage magnétique des ferromagnétiques en grains fins avec applications aux terres cuites. Ann. Geophys., 5:99-136.

Rochette, P., Fillion, G., Mattéi, J.-L., and Dekkers, M.J., 1990. Magnetic transition at 30-34 Kelvin in pyrrhotite: insight into a widespread occurrence of this mineral in rocks. Earth Planet. Sci. Lett., 98:319-328.

Date of initial receipt: 12 December 1995

Date of acceptance: 26 August 1996

Ms 154SR-134 